\title{
Mixed Convection Squeezing Flow of Nanofluids in a Rotating Channel with Thermal Radiation
}

\author{
Wankui Bu, ${ }^{1}$ Hui Xu, ${ }^{1}$ Ilyas Khan ${ }^{(D},{ }^{2}$ Sheikh Irfan Ullah Khan, ${ }^{3}$ and Anwar Zeb ${ }^{3}$ \\ ${ }^{1}$ College of Urban Construction, Heze University, Heze 274015, China \\ ${ }^{2}$ Department of Mathematics, College of Science Al-Zulfi, Majmaah University, Al-Majmaah 11952, Saudi Arabia \\ ${ }^{3}$ Department of Mathematics, COMSATS University of Islamabad, Abbottabad Campus, Khyber Pakhtunkhwa, Pakistan
}

Correspondence should be addressed to Ilyas Khan; i.said@mu.edu.sa

Received 22 November 2021; Revised 9 January 2022; Accepted 17 January 2022; Published 18 February 2022

Academic Editor: Saima Arshed

Copyright ( $\odot 2022$ Wankui Bu et al. This is an open access article distributed under the Creative Commons Attribution License, which permits unrestricted use, distribution, and reproduction in any medium, provided the original work is properly cited.

In the present study, 3-dimensional squeezing movement in a circling conduit under the stimulus effective Prandtl number with the aid of thermal radiation is taken into account. Water and ethylene glycol are the base fluids along with gamma-alumina nanoparticles. The coupled nonlinear system of PDEs is transformed into a system of ODEs with the support of some appropriate resemblance alterations. Then, the explanation was obtained numerically by the Runge-Kutta-Fehlberg (RKF) method. The emerging parameters such as quotient of the electric magnetic field to viscous forces $(M)$, Prandtl number (Pr), and Reynolds number (Re), along with physical parameters such as the Nusselt number and skin friction coefficient, will be integrated graphically. The Prandtl number is important for regulating the momentum and thermal boundary layers. As a result, the effect of the effective Prandtl number on the nanoboundary layer and laminar incompressible flow of $\gamma \mathrm{Al}_{2} \mathrm{O}_{3}-\mathrm{H}_{2} \mathrm{O}$ and $\gamma \mathrm{Al}_{2} \mathrm{O}_{3}-$ $\mathrm{C}_{2} \mathrm{H}_{6} \mathrm{O}_{2}$ nanoparticles is considered. The impact of the radiation parameter (Rd) favors the temperature distribution. Furthermore, the thermal conductance enriches with the enhancement of solid volume fraction.

\section{Introduction}

Mixed convection occurs when the free or natural convection (induced by buoyancy forces) and the forced convection (induced by external means) act together in a heat transfer phenomenon. An internal flow, such as a pipe flow, is surrounded by solid walls that can limit the development of its boundary layer. External flows, on the contrary, occur over bodies submerged in an unbounded fluid, allowing the flow boundary layer to freely develop in one direction. Flows over air foils, ship hulls, turbine blades, and other structures are examples. It carries great importance due to its application in nuclear reactors, electronic cooling, and solar energy systems. For heat management and control of such systems, natural convection alone is sometimes insufficient; hence, forced convection is required. Convection in a cavity is also of great importance which has two aspects under consideration, one which assists forced flow motion in the channel with natural convection in the cavity and the other that opposes it. It has a significant impact in the field of heat transmission and has a wide range of applications, including furnaces, ovens, and combustion chambers, as well as incinerators. However, the mixed convection is causing concern, particularly among electronic system manufacturers. In fact, as a result of reaching more and better hardware potential, a greater and more effective cooling system for boards and components was required. Sharif [1] studied laminar mixed convection in a shallow inclined cavity with the hot upper wall and cool lower wall. Mahmoodi $[2,3]$ investigated mixed convection flow of water$\mathrm{Al}_{2} \mathrm{O}_{3}$ nanofluid in a rectangular cavity. He observed that due to the presence of nanoparticles in the base fluid, heat transfer rate increases for all ranges of the Richardson number under consideration. In recent times, Khan et al. [4-6] examined the MHD convection squeezing flow of nanofluids under the influence of mixed convection.

The fluid particles must deform under the influence of squeezing flow based on the squeezing rate, for example, the 
flow of blood platelets in blood vessels with a diameter equal to or slightly bigger than the size of platelets. In such a case, when blood cells flow between those narrow gaps, they get squeezed and hence deformed. Chen and Skalak studied Stoke's flow having spheroidal particles in a cylindrical tube in effect of both wide and narrow gaps [7]. Squeezing a sample between parallel plates has long been used to characterize the rheological behavior of soft, clear viscous materials, and small-amplitude oscillatory squeezing has recently been proposed as a method for determining the linear viscoelastic properties of molten polymers and suspensions. The biggest and most significant advantage of a squeeze flow rheometer over a rotational device is its simplicity as it has no air bearing and is significantly less expensive and simple to use. Squeezing flow is not an isometric flow; hence, devices that use this deformation for nonNewtonian fluids can only be used qualitatively unless a constitutive model is given. Rotating channel has great applications in geophysics, and astrophysics also has great importance in turbo machines, vortex-type MHD power generators, nuclear reactors using the liquid metal coolant, material processing, etc.

Due to various applications in practical situations, the study of fluid flow on the surface of a rotating disc has attracted a lot of interest from researchers all over the world. Fluid flow over the surface of a spinning disc is frequently used for lubrication reasons in electric power generation systems, rotating machinery, corotating turbines, chemical processes, and computer storage in the fields of aerodynamics engineering and geothermal technology.

MHD flow analysis is important because the magnetic field acting on the viscid current of an electrically transmitting liquid is used in a variety of industrial techniques, including the processing of magnetized materials, crude oil refining, MHD electric propagation, glass fabrication, paper production, and geophysical sciences, to name a few. The MHD flow issue going through an enhanced upright plate has a wide range of applications, including filtration, drying porous materials in textile manufacturing, and chemical impregnation of porous materials.

A fluid which contains small nanometer-sized particles in a suspension called nanoparticles is termed as a nanofluid. These particles are usually made of metals, oxides, carbides, or carbon nanotubes. Commonly used nanofluids are water, ethylene glycol, and oil. Choi of the Argonne National Laboratory [8] was the first who proposed the term nanofluids in 1995 in the USA. The presence of these nanoparticles in nanofluids increases the thermal properties of the fluids. They have many applications such as from houses such as domestic refrigerator, chiller, heat exchanger in grinding, boiling, and machining fuel gas temperature reduction to large scale such as microelectronic fuel cells, hybrid powered engines, thermal management engine cooling, pharmaceutical processes, ultrasonic field display, and solar collectors (because of their optical properties). Routbort reviewed a project in 2008 that employed nanofluids for industrial cooling that could result in great energy savings and resulting emission reductions. Kim et al. $[9,10]$ at the Nuclear Science and Engineering Department of the Massachusetts Institute of Technology (MIT) performed a study to assess the feasibility of nanofluids in nuclear applications by improving the performance of any water-cooled nuclear system. Kandaswamy et al. [11] portrayed the impact of convection near its density maximum with partially active vertical walls. In addition to enhance the thermal conductivity, nanofluids also have many vast ranges of applications in various fields including energy, mechanical, and biomedical fields, reducing pollution, heating buildings, space and defense, transportation, etc. Modern researchers synthesize nanofluids by two famous ways that are two-step and one-step methods. Two-step method is a very renowned method in which nanoparticles, nanotubes, or nanofibers are first synthesized as a powder in a dry form, and then it will further be immersed in the fluid with the help of intensive magnetic force agitation, ultrasonic agitation, high-shear mixing, homogenizing, and ball milling. As it is a convenient and widely used method, it still lacks the ability to produce the nanoparticles of greater stability, and due to this loophole, the researchers' interests dragged towards a more advanced method that is the one-step method; Eastman developed a one-step physical vapor condensation method to prepare $\mathrm{Cu}$ / ethylene glycol nanofluids. The one factor of this process is that it avoids the accumulation of nanoparticles, and hence, stability increased [12-19].

Sketching in mind all the above-discussed detailed efforts and extensive work, we will further go through and extend the idea to three-dimensional mixed convection squeezing flow of nanofluids with a nonlinear term of temperature induced over here. The required gained model will be solved iteratively with the RKF (Runge-Kutta-Fehlberg) scheme. The rate of change of displacement and the temperature outcomes will be consequent by alumina and gamma-alumina nanoparticles with different base fluids such as $\mathrm{H}_{2} \mathrm{O}$ and $\mathrm{C}_{2} \mathrm{H}_{6} \mathrm{O}_{2}$ and also depicted graphically. In spite of these two outcomes, we will be focusing our devotion to evaluate wide-ranging consequences of embedding and physical parameter realistically.

\section{Mathematical Formulation}

Contemplate a time-dependent 3D squeezing flow of Newtonian base fluids, water and ethylene glycol, which are electrically conducting and incompressible, adjourned by the alumina and gamma-alumina nanoparticles in a rotating channel, in between two plates, set in parallel position. This position is in such an order that the bottom plate is stretched with the velocity $U_{w}=a x / 1-b t$ at $y=0$ with the constant temperature $T_{w}$ being maintained, while the higher plate is at the fluctuating distance $h(t)=\sqrt{v(1-b t) / a}$, where the temperature is $T_{h} . V_{h}=\mathrm{d} h / \mathrm{d} t$ represents the velocity of squeezing flow in the $y$-negative direction. The base fluids and the walls are rotating in counterclockwise in the constructive $y$-axis with the transverse component of velocity $\vec{\Omega}=\omega j /(1-b t) . B(t)=B_{0} / \sqrt{(1-b t)}$ signifies the variable transverse magnetic field executed perpendicularly. The suction of nanofluid occurred at the lower plate at $y=0$. The thermophysical possessions of nanofluids are taken from Khan et al. [3]. The geometry of the flow prototype is given in Figure 1. 


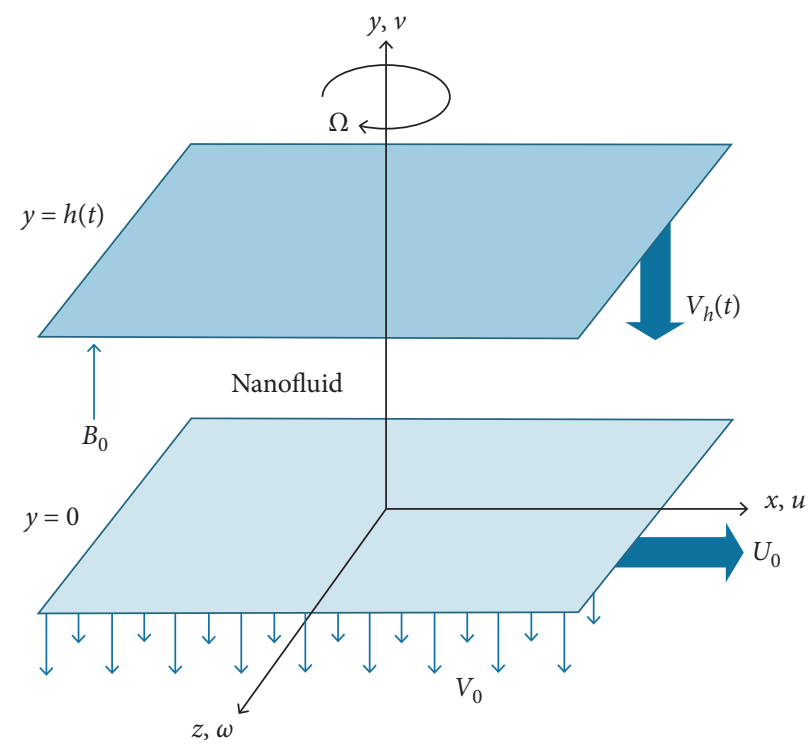

FIgURE 1: Geometry of the problem.

The precise model of mixed convection squeezing flow of electrically conducting incompressible nanofluids, with a nonlinear temperature term, in the presence of applied magnetic field is distinct by the succeeding set of PDEs [4]:

$$
\begin{aligned}
\frac{\partial u}{\partial x}+\frac{\partial u}{\partial y}= & 0 \\
\frac{\partial u}{\partial t}+u \frac{\partial u}{\partial x}+v \frac{\partial u}{\partial y}+2 \frac{\omega}{(1-b t)} w= & -\frac{1}{\rho_{n f}} \frac{\partial p}{\partial x} \\
& +v_{n f}\left(\frac{\partial^{2} u}{\partial x^{2}}+\frac{\partial^{2} u}{\partial y^{2}}\right)-\frac{\sigma_{n f} B_{0}^{2}}{\rho_{n f}(1-b t)} u+\frac{g(\rho \beta)_{n f}}{\rho_{n f}}\left(T-T_{0}\right), \\
\frac{\partial v}{\partial t}+u \frac{\partial v}{\partial x}+v \frac{\partial v}{\partial y}= & -\frac{1}{\rho_{n f}} \frac{\partial p}{\partial y}+v_{n f}\left(\frac{\partial^{2} v}{\partial x^{2}}+\frac{\partial^{2} v}{\partial y^{2}}\right) \\
\frac{\partial u}{\partial t}+u \frac{\partial u}{\partial x}+v \frac{\partial u}{\partial y}-2 \frac{\omega}{(1-b t)} u & =v_{n f}\left(\frac{\partial^{2} w}{\partial x^{2}}+\frac{\partial^{2} w}{\partial y^{2}}\right)-\frac{\sigma_{n f} B_{0}^{2}}{\rho_{n f}(1-b t)} w, \\
\frac{\partial T}{\partial t}+u \frac{\partial T}{\partial x}+v \frac{\partial T}{\partial y}= & -\frac{k_{n f}}{\left(\rho C_{p}\right)_{n f}}\left(\frac{\partial^{2} T}{\partial x^{2}}+\frac{\partial^{2} T}{\partial y^{2}}\right)+\frac{16 \sigma^{*} T_{\infty}^{3}}{3 k^{*}\left(\rho c_{p}\right)_{n f}} \frac{\partial^{2} T}{\partial y^{2}} .
\end{aligned}
$$

The apposite boundary surroundings for the prototype are 


$$
\begin{aligned}
& u=U_{w}=\frac{a x}{(1-b t)}, \\
& v=V_{w}=-\frac{V_{0}}{(1-b t)}, \quad \text { at } y=0 \text {, } \\
& w=0 \text {, } \\
& T=T_{w}, \\
& u=0 \text {, } \\
& v=V_{h}=-\frac{a}{2}\left(\frac{v}{\alpha(1-a t)}\right)^{1 / 2}, \\
& w=0 \text {, } \\
& T=T_{h} \text {, } \\
& \text { at } y=h(t) \text {. }
\end{aligned}
$$

In equations (1) up to (7), $u, v$, and $w$ are the rate of change components along $x_{-}, y_{\text {-, }}$, and $z$-directions correspondingly, $B_{0}$ is the magnetic field, $p$ denotes the pressure, $b$ is the distinctive limit of time reciprocal length $t$ and $b t<1$, $\sigma_{n f}$ is the effective electrically conducting parameter, magnitude of acceleration is $g, T$ is the liquid's temperature, $v_{n f}$ is the effective kinematic viscosity of the nanofluid, $\rho_{n f}$ is the effective density of nanofluids, $k_{n f}$ is the effective thermal conductivity of nanofluids, mean absorption coefficient is $k^{*}, \sigma^{*}$ is the SB (Stefan-Boltzmann) constant, and $\left(C_{p}\right)_{n f}$ is the heat capacity of nanofluids. For the present flow prototype, use the following effective models for dynamic viscosity, density, electrical conductivity, thermal conductivity, and heat capacitance [3].

$$
\begin{gathered}
\frac{\rho_{n f}}{\rho_{f}}=\left\{(1-\phi)+\phi \frac{\rho_{s}}{\rho_{f}}\right\}, \\
\frac{\left(\rho C_{p}\right)_{n f}}{\left(\rho C_{p}\right)_{f}}=\left\{(1-\phi)+\phi \frac{\left(\rho C_{p}\right)_{s}}{\left(\rho C_{p}\right)_{f}}\right\},
\end{gathered}
$$

where $\phi$ is termed as the solid size segment of the nanoparticles.

The active viscosity of the nanoparticles is demarcated as

$$
\begin{aligned}
& \frac{\mu_{n f}}{\mu_{f}}=123 \phi^{2}+7.3 \phi+1\left(\text { for } \gamma \mathrm{Al}_{2} \mathrm{O}_{3}-\mathrm{H}_{2} \mathrm{O}\right), \\
& \frac{\mu_{n f}}{\mu_{f}}=306 \phi^{2}-0.19 \phi+1\left(\text { for } \gamma \mathrm{Al}_{2} \mathrm{O}_{3}-\mathrm{C}_{2} \mathrm{H}_{6} \mathrm{O}_{2}\right) .
\end{aligned}
$$

The effective thermal conductivity of the nanoparticles is taken as

$$
\begin{aligned}
& \frac{k_{n f}}{k_{f}}=4.97 \phi^{2}-2.72 \phi+1,\left(\text { for } \gamma \mathrm{Al}_{2} \mathrm{O}_{3}-\mathrm{H}_{2} \mathrm{O}\right), \\
& \frac{k_{n f}}{k_{f}}=28.905 \phi^{2}-2.8273 \phi+1\left(\text { for } \gamma \mathrm{Al}_{2} \mathrm{O}_{3}-\mathrm{C}_{2} \mathrm{H}_{6} \mathrm{O}_{2}\right) .
\end{aligned}
$$

The effective Prandtl number of the nanoparticles is given by

$$
\begin{aligned}
& \frac{\operatorname{Pr}_{n f}}{\operatorname{Pr}_{f}}=82.1 \phi^{2}+3.9 \phi+1\left(\text { for } \gamma \mathrm{Al}_{2} \mathrm{O}_{3}-\mathrm{H}_{2} \mathrm{O}\right), \\
& \frac{\operatorname{Pr}_{n f}}{\operatorname{Pr}_{f}}=254.3 \phi^{2}-3 \phi+1\left(\text { for } \gamma \mathrm{Al}_{2} \mathrm{O}_{3}-\mathrm{C}_{2} \mathrm{H}_{6} \mathrm{O}_{2}\right) .
\end{aligned}
$$

Furthermore, the physical and the thermal properties of base fluids such as $\mathrm{H}_{2} \mathrm{O}$ and $\mathrm{C}_{2} \mathrm{H}_{6} \mathrm{O}_{2}$ along with alumina nanoparticles are given in Table 1 .

Here, the comparative alterations are defined in the directive to reduce the following boundary layer equation:

$$
\begin{aligned}
& \eta=\sqrt{\frac{a}{v_{f}(1-b t)}} y, \\
& u=\frac{a x}{(1-b t)} f^{\prime}(\eta), \\
& \nu=-\left(\frac{a v}{(1-b t)}\right)^{1 / 2} f(\eta), \\
& \theta=\frac{T-T_{h}}{T_{w}-T_{h}}
\end{aligned}
$$


Table 1: Properties of nanoparticles and base fluids.

\begin{tabular}{|c|c|c|c|c|c|}
\hline Model & $\rho\left(\mathrm{kgm}^{-3}\right)$ & $C_{p}\left(\mathrm{~kg}^{-1} \mathrm{~K}^{-1}\right)$ & $k\left(\mathrm{Wm}^{-1} \mathrm{~K}^{-1}\right)$ & $\sigma$ & $\operatorname{Pr}$ \\
\hline $\mathrm{H}_{2} \mathrm{O}$ & 997.1 & 4179 & 0.613 & 0.005 & 6.96 \\
\hline $\mathrm{C}_{2} \mathrm{H}_{6} \mathrm{O}_{2}$ & 1116.6 & 2382 & 0.249 & $5.5 * 10^{-6}$ & 204 \\
\hline $\mathrm{Al}_{2} \mathrm{O}_{3}$ & 3970 & 765 & 40 & $3.5 * 10^{7}$ & - \\
\hline
\end{tabular}

The ordinary differential equations in the nondimensionalized form are gained by dropping the governing $\gamma \mathrm{Al}_{2} \mathrm{O}_{3}-\mathrm{H}_{2} \mathrm{O}$ model: boundary layer equations into the simplest form as follows:

$$
\begin{array}{r}
f^{i v}(\eta)-B_{1}\left[\begin{array}{c}
f^{\prime}(\eta) f^{\prime \prime}(\eta)-f(\eta) f^{\prime \prime \prime}(\eta) \\
+\frac{\beta}{2}\left(3 f^{\prime \prime}(\eta)+\eta f^{\prime \prime \prime}(\eta)\right)+2 R g^{\prime}(\eta)
\end{array}\right]-B_{2} M^{2} f^{\prime \prime}(\eta)+B_{3} \lambda \theta^{\prime}(\eta)=0, \\
g^{\prime \prime}(\eta)-B_{1}\left[\begin{array}{c}
f(\eta) g^{\prime}(\eta)-f^{\prime}(\eta) g(\eta) \\
+\beta\left(g(\eta)+\frac{\eta}{2} g^{\prime}(\eta)\right)+2 R f^{\prime}(\eta)
\end{array}\right]-B_{2} M^{2} g^{\prime}(\eta)=0, \\
{\left[1+\frac{R d}{4.97 \phi^{2}+2.72 \phi+1}\right] \theta^{\prime \prime}(\eta)+(\operatorname{Pr})_{n f} B_{4}\left[f(\eta) \theta^{\prime}(\eta)-\frac{\beta}{2} \eta \theta^{\prime}(\eta)\right]=0 .}
\end{array}
$$

$\gamma \mathrm{Al}_{2} \mathrm{O}_{3}-\mathrm{C}_{2} \mathrm{H}_{6} \mathrm{O}_{2}$ model:

$$
\begin{gathered}
f^{i v}(\eta)-C_{1}\left[\begin{array}{c}
3 f^{\prime}(\eta) f^{\prime \prime}(\eta)-f(\eta) f^{\prime \prime \prime}(\eta) \\
+\frac{\beta}{2}\left(3 f^{\prime \prime}(\eta)+\eta f^{\prime \prime \prime}(\eta)\right)+2 R g^{\prime}(\eta)
\end{array}\right]-C_{2} M^{2} f^{\prime \prime}(\eta)+C_{3} \lambda \theta^{\prime}(\eta)=0, \\
g^{\prime \prime}(\eta)-C_{1}\left[\begin{array}{c}
f(\eta) g^{\prime}(\eta)-f^{\prime}(\eta) g(\eta) \\
+\beta\left(g(\eta)+\frac{\eta}{2} g^{\prime}(\eta)\right)+2 R f^{\prime}(\eta)
\end{array}\right]-C_{2} M^{2} g^{\prime}(\eta)=0 \\
{\left[1+\frac{R d}{28.906 \phi^{2}+2.8272 \phi+1}\right] \theta^{\prime \prime}(\eta)+(\operatorname{Pr})_{n f} C_{4}\left[f(\eta) \theta^{\prime}(\eta)-\frac{\beta}{2} \eta \theta^{\prime}(\eta)\right]=0 .}
\end{gathered}
$$

The flow conditions at the boundaries are 


$$
\begin{aligned}
& \left\{\begin{array}{l}
f(\eta)=S, \\
f^{\prime}(\eta)=1, \\
g(\eta)=0, \\
\theta(\eta)=1,
\end{array} \text { at } \eta=0,\right. \\
& \left\{\begin{array}{l}
f(\eta)=\frac{\beta}{2}, \\
f^{\prime}(\eta)=0, \\
g(\eta)=0, \\
\theta(\eta)=0,
\end{array}\right.
\end{aligned}
$$$$
\beta=\frac{b}{a}
$$$$
M^{2}=\frac{\sigma \beta_{0}^{2}}{a \rho_{f}}
$$$$
R=\frac{\omega}{b}
$$

$$
\begin{array}{lc}
\text { where } & \\
B_{1}=\frac{\left\{(1-\phi)+\phi\left(\rho_{s} / \rho_{f}\right)\right\}}{\left(123 \phi^{2}+7.3 \phi+1\right)}, & P_{r}=\frac{(\mu C p)_{f}}{k_{f}}, \\
B_{2}=\frac{\left(\sigma_{s}+2 \sigma_{f}\right)+2 \phi\left(\sigma_{s}-\sigma_{f}\right) /\left(\sigma_{s}+2 \sigma_{f}\right)-\phi\left(\sigma_{s}-\sigma_{f}\right)}{\left(123 \phi^{2}+7.3 \phi+1\right)}, & \begin{array}{l}
V_{0} \\
a h
\end{array}
\end{array}
$$$$
B_{3}=\frac{\left\{(1-\phi)+\phi\left((\rho \beta)_{s} /(\rho \beta)_{f}\right)\right\}}{\left(123 \phi^{2}+7.3 \phi+1\right)},
$$$$
B_{4}=\frac{\left\{(1-\phi)+\phi\left(\left(\rho C_{p}\right)_{s} /\left(\rho C_{p}\right)_{f}\right)\right\}}{\left(4.97 \phi^{2}+2.72 \phi+1\right)},
$$$$
C_{1}=\frac{\left\{(1-\phi)+\phi\left(\rho_{s} / \rho_{f}\right)\right\}}{\left(306 \phi^{2}-0.19 \phi+1\right)}
$$$$
C_{2}=\frac{\left(\sigma_{s}+2 \sigma_{f}\right)+2 \phi\left(\sigma_{s}-\sigma_{f}\right) /\left(\sigma_{s}+2 \sigma_{f}\right)-\phi\left(\sigma_{s}-\sigma_{f}\right)}{\left(306 \phi^{2}-0.19 \phi+1\right)},
$$$$
C_{3}=\frac{\left\{(1-\phi)+\phi\left((\rho \beta)_{s} /(\rho \beta)_{f}\right)\right\}}{\left(306 \phi^{2}-0.19 \phi+1\right)},
$$$$
C_{4}=\frac{\left\{(1-\phi)+\phi\left(\left(\rho C_{p}\right)_{s} /\left(\rho C_{p}\right)_{f}\right)\right\}}{\left(28.906 \phi^{2}+2.8272 \phi+1\right)} .
$$$$
\operatorname{Re}=\frac{x U_{w}}{v_{f}}
$$$$
G_{r}=\frac{g \beta_{f} T_{0} x^{3}}{v_{f}^{2}}
$$$$
\lambda=\frac{G_{r}}{\operatorname{Re}^{2}},
$$

The measures such as rate of heat transfer and skin friction coefficient are specified as

$$
C_{f}=-\frac{2 \mu_{n f}}{\rho_{f} U_{w 0}^{2}}\left(\frac{\partial u}{\partial y}\right)_{y=0}
$$

Using this, we have the skin friction coefficient as follows.

For $\gamma \mathrm{Al}_{2} \mathrm{O}_{3}-\mathrm{H}_{2} \mathrm{O}$,

$\left(C_{f}\right)_{y=0}=\sqrt{\operatorname{Re}} C_{f}^{*}=\frac{f^{\prime \prime}(0)\left(123 \phi^{2}+7.3 \phi+1\right)}{\left\{(1-\phi)+\phi\left(\rho_{s} / \rho_{f}\right)\right\}}=\frac{f^{\prime \prime}(0)}{B_{1}}$.

For $\gamma \mathrm{Al}_{2} \mathrm{O}_{3}-\mathrm{C}_{2} \mathrm{H}_{6} \mathrm{O}_{2}$,

$\left(C_{f}\right)_{y=0}=\sqrt{\operatorname{Re}} C_{f}^{*}=\frac{f^{\prime \prime}(0)\left(306 \phi^{2}-0.19 \phi+1\right)}{\left\{(1-\phi)+\phi\left(\rho_{s} / \rho_{f}\right)\right\}}=\frac{f^{\prime \prime}(0)}{C_{1}}$.

By using the comparison variables and active thermophysical properties, we attain the subsequent formula of the Nusselt number as

$$
\mathrm{Nu}=\frac{x q_{w}}{k_{f}\left(T_{w}-T_{h}\right)} .
$$

The nondimensional limitations entrenched in the flow prototype are specified as

Using this, we have the required form of the Nusselt number as follows. 
For $\gamma \mathrm{Al}_{2} \mathrm{O}_{3}-\mathrm{H}_{2} \mathrm{O}$ :

At the lower plate,

$$
(\mathrm{Nu})_{y=0}=(1-a t)^{1.5} \mathrm{Nu}^{*}=-\left(4.97 \phi^{2}+2.72 \phi+1\right) \theta^{\prime}(0) \text {. }
$$

At the upper plate,

$$
(\mathrm{Nu})_{y=h(t)}=(1-a t)^{1.5} \mathrm{Nu}^{*}=-\left(4.97 \phi^{2}+2.72 \phi+1\right) \theta^{\prime}(1) \text {. }
$$

For $\gamma \mathrm{Al}_{2} \mathrm{O}_{3}-\mathrm{C}_{2} \mathrm{H}_{6} \mathrm{O}_{2}$ :

At the lower plate,

$$
\begin{aligned}
(\mathrm{Nu})_{y=0} & =(1-a t)^{1.5} \mathrm{Nu}^{*} \\
& =-\left(28.905 \phi^{2}+2.8273 \phi+1\right) \theta^{\prime}(0)
\end{aligned}
$$

At the upper plate,

$$
\begin{aligned}
(\mathrm{Nu})_{y=h(t)} & =(1-a t)^{1.5} \mathrm{Nu}^{*} \\
& =-\left(28.905 \phi^{2}+2.8273 \phi+1\right) \theta^{\prime}(1) .
\end{aligned}
$$

\section{Solution of the Problem}

For explanation persistence of the existing flow prototype, we utilized the iterative scheme of RK along with the shooting method. In order to summarize the flow mode, we take the subsequent conventions:

$$
\begin{aligned}
& c_{1}=f, \\
& c_{2}=f^{\prime}, \\
& c_{3}=f^{\prime \prime}, \\
& c_{4}=f^{\prime \prime \prime}, \\
& c_{5}=g, \\
& c_{6}=g^{\prime}, \\
& c_{7}=\theta, \\
& c_{8}=\theta^{\prime} .
\end{aligned}
$$

$$
\begin{aligned}
& f^{i v}(\eta)=B_{1}\left[\begin{array}{c}
f^{\prime}(\eta) f^{\prime \prime}(\eta)-f(\eta) f^{\prime \prime \prime}(\eta) \\
+\frac{\beta}{2}\left(3 f^{\prime \prime}(\eta)+\eta f^{\prime \prime \prime}(\eta)\right)+2 R g^{\prime}(\eta)
\end{array}\right]+B_{2} M^{2} f^{\prime \prime}(\eta)+B_{3} \lambda \theta^{\prime}(\eta), \\
& g^{\prime \prime}(\eta)=-B_{1}\left[\begin{array}{c}
f(\eta) g^{\prime}(\eta)-f^{\prime}(\eta) g(\eta) \\
+\beta\left(g(\eta)+\frac{\eta}{2} g^{\prime}(\eta)\right)+2 R f^{\prime}(\eta)
\end{array}\right]+B_{2} M^{2} g^{\prime}(\eta), \\
& \theta^{\prime \prime}(\eta)=-\left[1+\frac{R d}{4.97 \phi^{2}+2.72 \phi+1}\right]^{-1}(\operatorname{Pr})_{n f} B_{4}\left[f(\eta) \theta^{\prime}(\eta)-\frac{\beta}{2} \eta \theta^{\prime}(\eta)\right] .
\end{aligned}
$$

Using the conditions in (26), we have the subsequent structure of the first-order ODE: 


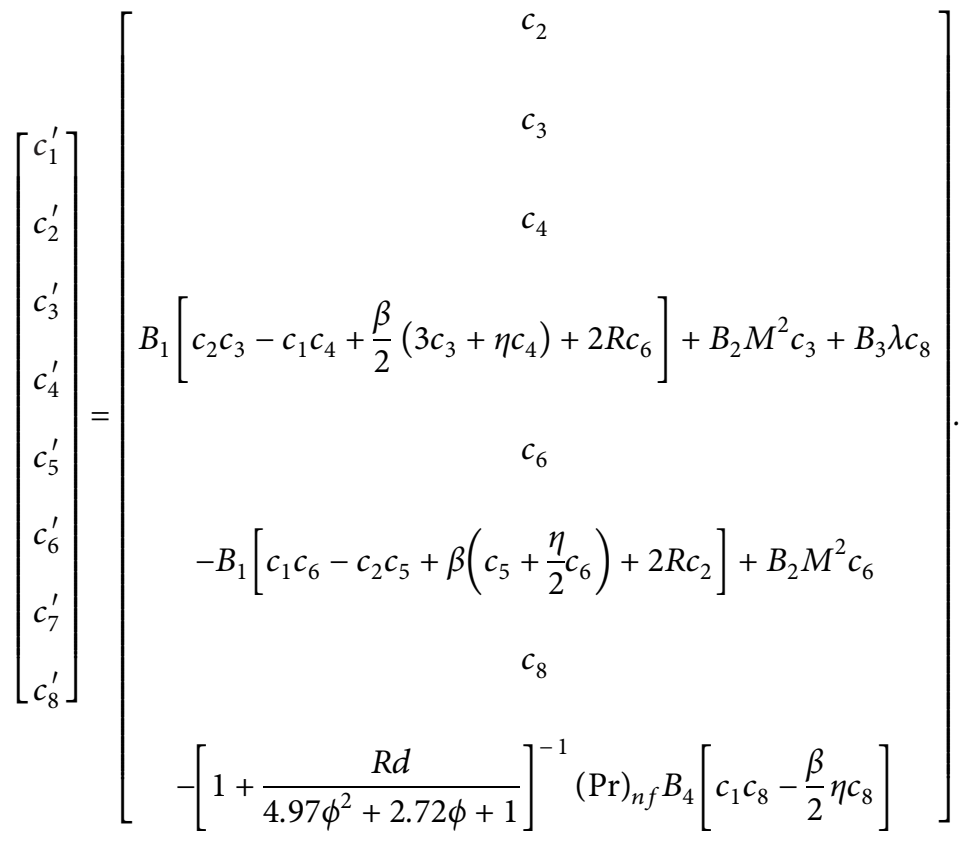

The associated boundary conditions are

$$
\left[\begin{array}{l}
c_{1} \\
c_{2} \\
c_{3} \\
c_{4} \\
c_{5} \\
c_{6} \\
c_{7} \\
c_{8}
\end{array}\right]=\left[\begin{array}{l}
S \\
1 \\
\underline{\beta} \\
0 \\
0 \\
1 \\
0
\end{array}\right] .
$$

Equations (28) and (29) can be computed with the aid of Mathematica 10.0.

In a similar fashion, we can solve the $\gamma \mathrm{Al}_{2} \mathrm{O}_{3}-\mathrm{C}_{2} \mathrm{H}_{6} \mathrm{O}_{2}$ nanofluid model.

\section{Results and Discussion}

In this part, the results are assessed with the help of graphic aids and tabularized ideals. These results are evaluated by different flow structures.

This subset comprises the variations in the rate of change fields $f(\eta), f^{\prime}(\eta)$ and transverse component of velocity $g(\eta)$ due to fluctuating suction limit $S$, quotient of $V_{0}$ to $b h$, squeeze parameter $\beta$, quotient of $\alpha$ to $b$ (where $b$ is the characteristic parameter), rotation parameter $R$, quotient of $\omega$ and $a$, and magnetic parameter $M$. The numerical results are depicted for $\gamma \mathrm{Al}_{2} \mathrm{O}_{3}-\mathrm{H}_{2} \mathrm{O}$ and $\gamma \mathrm{Al}_{2} \mathrm{O}_{3}-\mathrm{C}_{2} \mathrm{H}_{6} \mathrm{O}_{2}$ nanoparticles. It is imperious to remark that defining the factor $S>0$ represents the movement of the upper plate towards the lower one, and the factor $S<0$ signifies the measure of the lower plate away from the upper one. Figure 2 represents the possessions of rotation parameter $R$ on the velocity field $f(\eta)$ for $\gamma \mathrm{Al}_{2} \mathrm{O}_{3}-\mathrm{H}_{2} \mathrm{O}$ and $\gamma \mathrm{Al}_{2} \mathrm{O}_{3}-\mathrm{C}_{2} \mathrm{H}_{6} \mathrm{O}_{2}$.
Here, Figure 2(a) depicts the velocity field $f(\eta)$ for the increasing value of rotation parameter $R=1,4,8,12$. For $S>0$, one can see that axial velocity $f(\eta)$ decreases for the increasing value of rotation parameter $R$, while for $S<0$, the axial velocity increases for $R=1,4,8,12$.

Figure 3 represents the effects of rotation parameter $R$ on the velocity field gradient $f^{\prime}(\eta)$ for $\gamma \mathrm{Al}_{2} \mathrm{O}_{3}-\mathrm{H}_{2} \mathrm{O}$ and $\gamma \mathrm{Al}_{2} \mathrm{O}_{3}-\mathrm{C}_{2} \mathrm{H}_{6} \mathrm{O}_{2}$. Figure $3(\mathrm{a})$ depicts the velocity field gradient $f^{\prime}(\eta)$ for the increasing value of rotation parameter $R=1,4,12,16$. For $S>0$, one can see that velocity field gradient $f^{\prime}(\eta)$ decreases for the increasing value of rotation parameter $R$, and for $S<0$, the velocity field gradient decreases.

Figure 4 inspects the effects of rotation parameter $R$ for the transverse component of the velocity for $\gamma \mathrm{Al}_{2} \mathrm{O}_{3}-\mathrm{H}_{2} \mathrm{O}$ and $\gamma \mathrm{Al}_{2} \mathrm{O}_{3}-\mathrm{C}_{2} \mathrm{H}_{6} \mathrm{O}_{2}$. In Figure 4(a), it is elucidated that, in the presence of $\gamma \mathrm{Al}_{2} \mathrm{O}_{3}-\mathrm{C}_{2} \mathrm{H}_{6} \mathrm{O}_{2}$, the velocity field increases slowly (shown by dotted red lines), while in $\gamma \mathrm{Al}_{2} \mathrm{O}_{3}-\mathrm{H}_{2} \mathrm{O}$, it increases more rapidly for $S>0$, while in Figure 4(b), for $S<0$, the velocity field decreases, and the nanoparticles in water decrease more rapidly.

Figures 5-7 examine the effects of squeezing parameter $\beta$ for axial velocity $f(\eta)$, velocity field gradient $f^{\prime}(\eta)$, and the transverse component of velocity $g(\eta)$ for $\gamma \mathrm{Al}_{2} \mathrm{O}_{3}-\mathrm{H}_{2} \mathrm{O}$ and $\gamma \mathrm{Al}_{2} \mathrm{O}_{3}-\mathrm{C}_{2} \mathrm{H}_{6} \mathrm{O}_{2}$. Here, the behavior of nanoparticles of given nanofluids is quite dominant for $S>0$ as well as for $S<0$ for $\beta=0.1,0.3,0.5,0.7$ to axial velocity $f(\eta)$ and the transverse component of velocity $g(\eta)$. However, the impact of higher values of $\beta$ on radial velocity is different than that of the remaining. For $S>0$, upon incremental values of $\beta$, the radial velocity increases, and an opposite behavior is observed in the case of injection.

Figures 8-10 depict the effects of magnetic parameter $M$ for $\gamma \mathrm{Al}_{2} \mathrm{O}_{3}-\mathrm{H}_{2} \mathrm{O}$ and $\gamma \mathrm{Al}_{2} \mathrm{O}_{3}-\mathrm{C}_{2} \mathrm{H}_{6} \mathrm{O}_{2}$ on velocity field gradient $f^{\prime}(\eta)$, axial velocity $f(\eta)$, and the transverse component of the velocity $g(\eta)$. In Figure $8(\mathrm{a})$, one can 


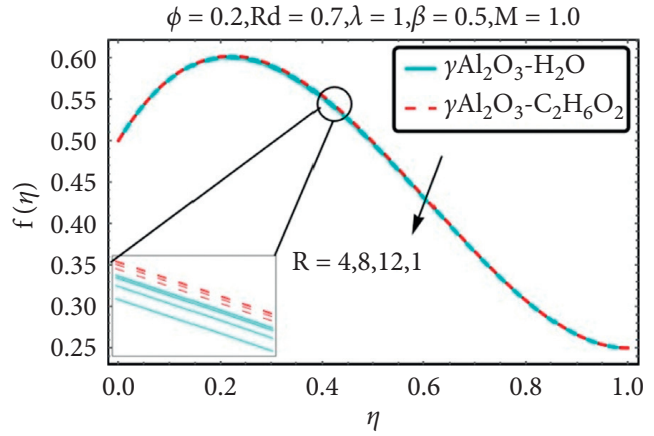

(a)

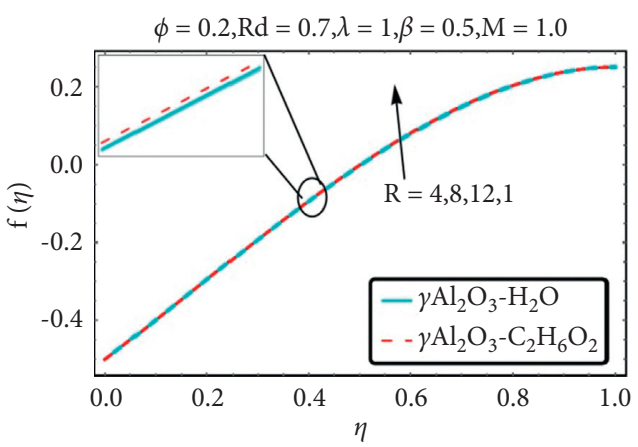

(b)

Figure 2: $R$ varying for $f$ with $S$ (for suction and injection).

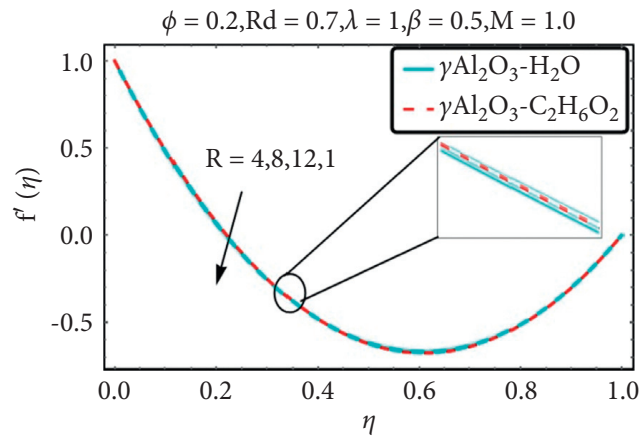

(a)

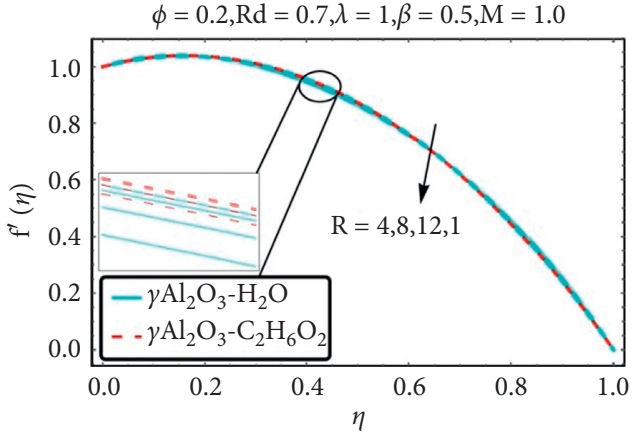

(b)

FIgURE 3: $R$ varying for $f$ with $S$ (suction and injection).

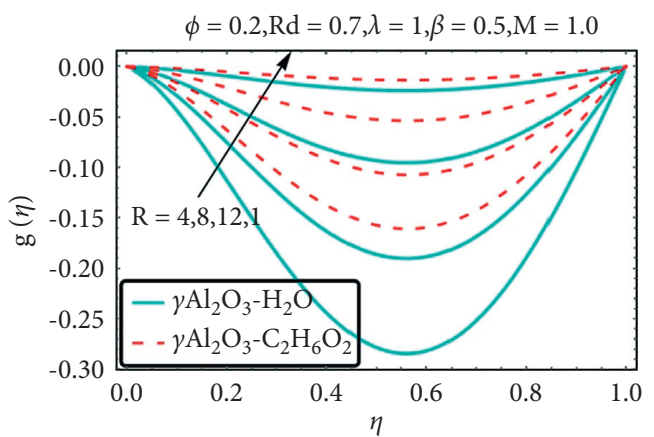

(a)

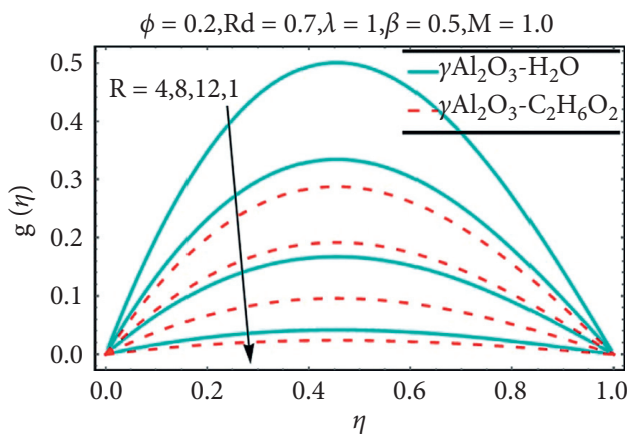

(b)

FIgURE 4: $R$ varying for $g(\eta)$ with $S$ (suction and injection).

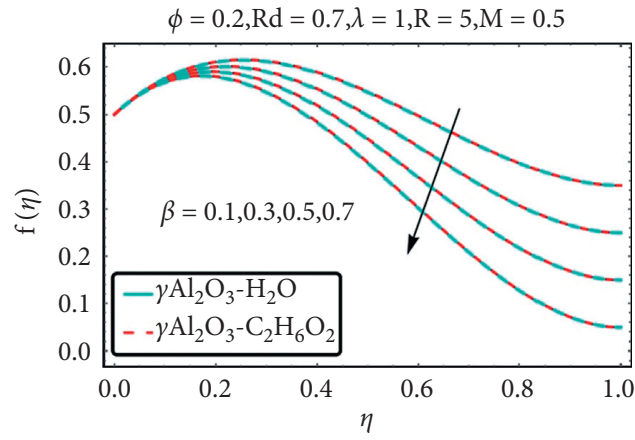

(a)

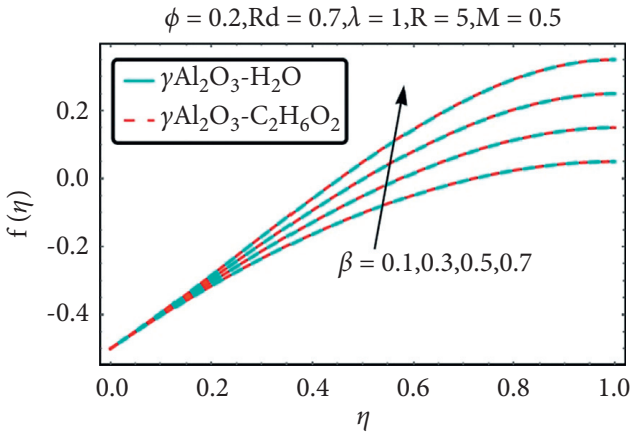

(b)

FIGURE 5: $\beta$ varying for $f$ with $S$ (suction and injection). 


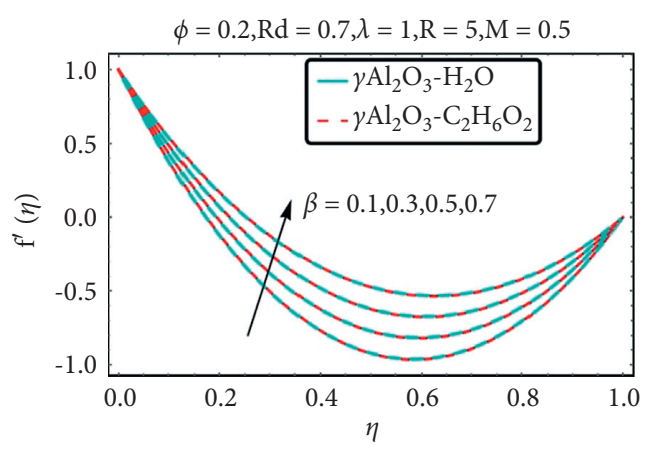

(a)

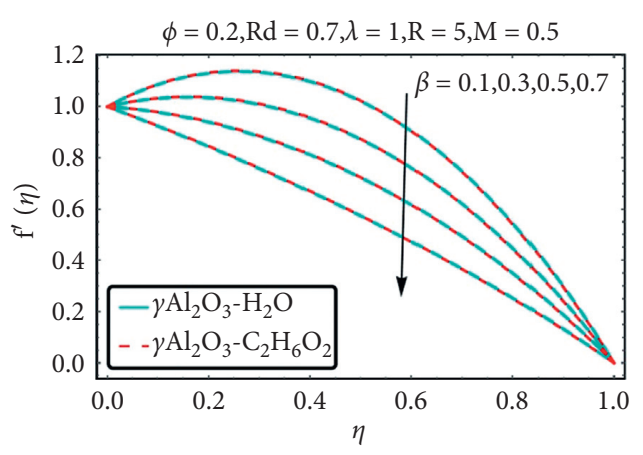

(b)

FIGURE 6: $\beta$ varying for $f^{\prime}$ with $S$ (suction and injection).

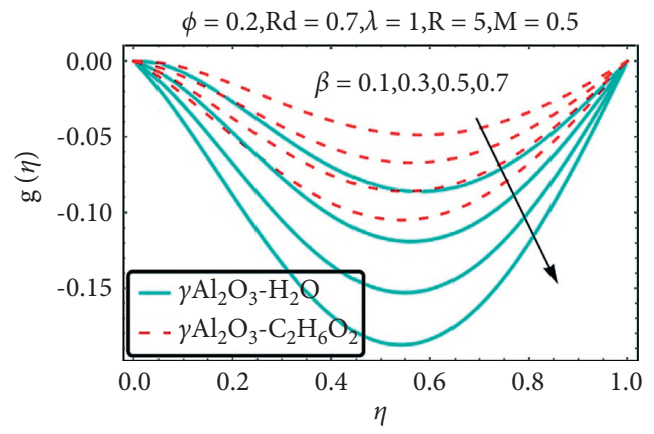

(a)

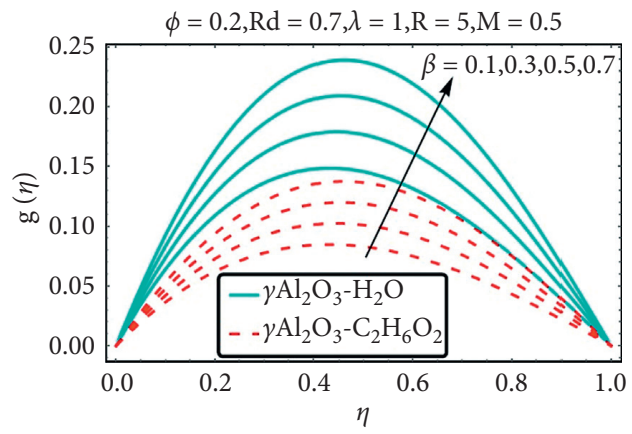

(b)

FIgURE 7: $\beta$ varying for $g$ with $S$ (suction and injection).

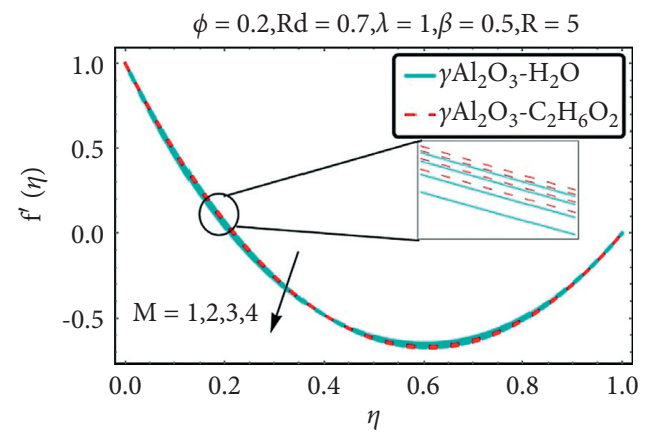

(a)

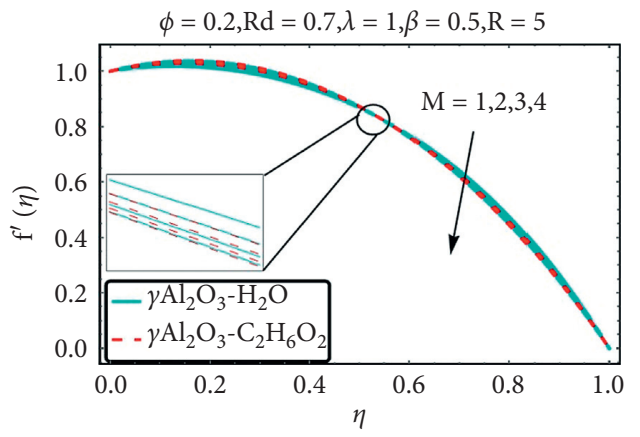

(b)

Figure 8: $M$ varying for $f^{\prime}$ with $S$ (suction and injection).

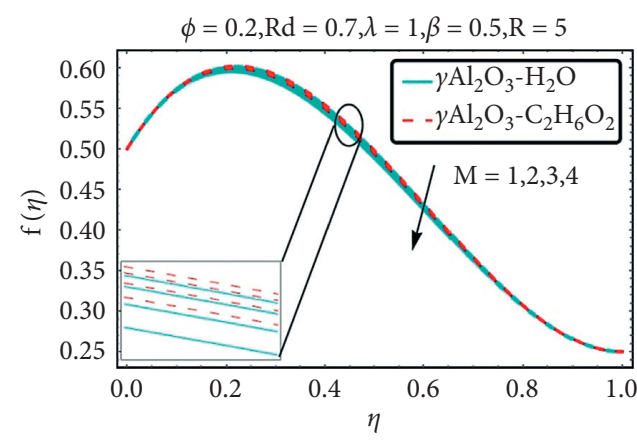

(a)

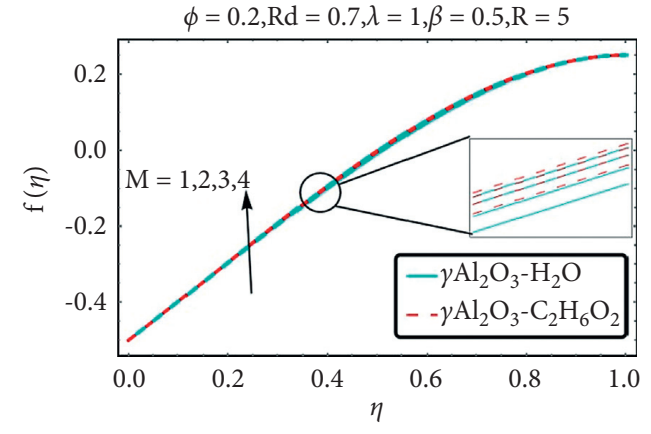

(b)

Figure 9: $M$ varying for $f$ with $S$ (suction and injection). 


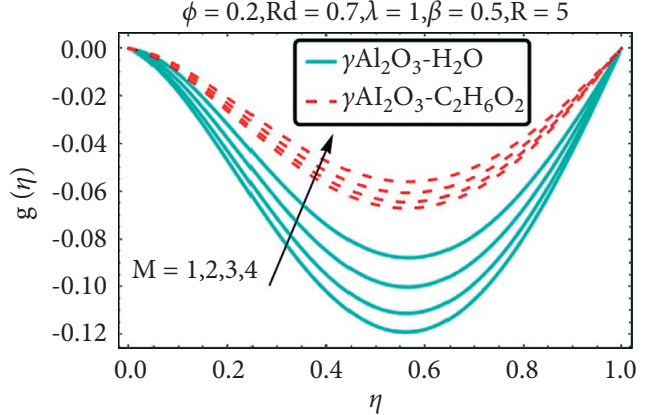

(a)

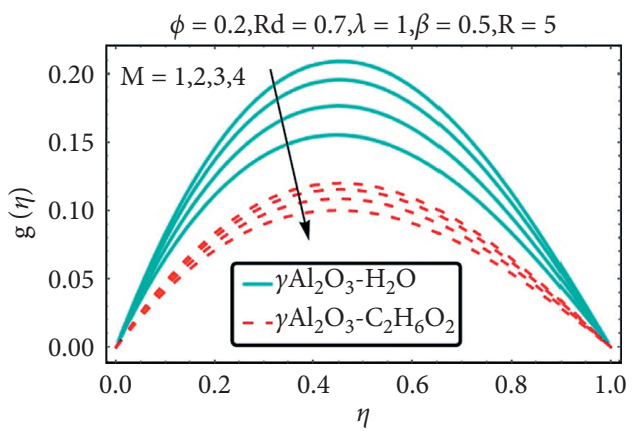

(b)

Figure 10: $M$ varying for $g$ with $S$ (suction and injection).

easily examine that, for the suction case, the magnitude of the velocity gradient increases with increasing values of the Hartmann number, while in Figure 8(b), for $S<0$, an opposite behavior is encountered for incremental values of $M$. However, in Figure 9, for higher values of $M$, the axial velocity for both $S>0$ and $S<0$ decreases due to the impedance of Lorentz forces. In Figure 10(a), the impact of angular velocity looks like that of radial velocity in Figure 8(a), while in the case of injection, the magnitude of $g(\eta)$ is decreased due to incremental values of the Hartmann number.

Figure 11 views the upshots of $\lambda$ quotient of the Grashof number to square root of the Reynolds number for the velocity field gradient $f^{\prime}(\eta)$ for $\gamma \mathrm{Al}_{2} \mathrm{O}_{3}-\mathrm{H}_{2} \mathrm{O}$ and $\gamma \mathrm{Al}_{2} \mathrm{O}_{3}-\mathrm{C}_{2} \mathrm{H}_{6} \mathrm{O}_{2}$. In Figure 11(a), it is noticed that, for $S>0$, the velocity field gradient first decreases rapidly, and then, at the area between 0.4 and 0.6 , its behavior instantly becomes adverse, and then onward, it increases for $\lambda=0,100,300$. On the contrary, in Figure 11(b), it is noticed that, for $S<0$, the velocity field gradient first increases rapidly, and then, at the region between 0.4 and 0.6 , its behavior instantly changes, and then onward, it decreases for $\lambda=0,100,300$.

Figure 12 checks the upshots of $\lambda$ quotient of $\mathrm{Gr}$ to $\sqrt{\mathrm{Re}}$ for the axial velocity $f(\eta)$ for $\gamma \mathrm{Al}_{2} \mathrm{O}_{3}-\mathrm{H}_{2} \mathrm{O}$ and $\gamma \mathrm{Al}_{2} \mathrm{O}_{3}-\mathrm{C}_{2} \mathrm{H}_{6} \mathrm{O}_{2}$. Here, one can examine that, upon incremental values of $\lambda$, the velocity field decreases for $S>0$, while in Figure 12(b), one can examine that the velocity field $f(\eta)$ increases for the increasing value of mixed convection parameter $\lambda=0,100,300$ for $S<0$.

Figure 13 inspects the effects of mixed convection parameter $\lambda$ for the transverse component of the velocity $g(\eta)$ for $\gamma \mathrm{Al}_{2} \mathrm{O}_{3}-\mathrm{H}_{2} \mathrm{O}$ and $\gamma \mathrm{Al}_{2} \mathrm{O}_{3}-\mathrm{C}_{2} \mathrm{H}_{6} \mathrm{O}_{2}$. In Figure 13(a), it is explicated that, in the occurrence of $\gamma \mathrm{Al}_{2} \mathrm{O}_{3}-\mathrm{H}_{2} \mathrm{O}$, the transverse component of velocity increases more rapidly, while in the case of $\gamma \mathrm{Al}_{2} \mathrm{O}_{3}-\mathrm{C}_{2} \mathrm{H}_{6} \mathrm{O}_{2}$, this impact slows down, while in Figure 13(b), for $S<0$, the velocity field decreases, and the nanoparticles adjoined with water decrease more rapidly than the particles based on ethylene glycol which shows the behavior of being decreasing quite slowly for $\lambda=0,100,300$.

Figures 14-16 check the effects of solid volume fraction $\phi$ for radial velocity $f^{\prime}(\eta)$, axial velocity, and the transverse component of the velocity $g(\eta)$ for $\gamma \mathrm{Al}_{2} \mathrm{O}_{3}-$ $\mathrm{H}_{2} \mathrm{O}$ and $\gamma \mathrm{Al}_{2} \mathrm{O}_{3}-\mathrm{C}_{2} \mathrm{H}_{6} \mathrm{O}_{2}$. In Figure $14(\mathrm{a})$, it is clarified that, in the presence of $\gamma \mathrm{Al}_{2} \mathrm{O}_{3}-\mathrm{C}_{2} \mathrm{H}_{6} \mathrm{O}_{2}$, the velocity field initially decreases, and at the region from 0.4 to 0.6 , a variation occurs, and the velocity field increases onward for $S>0$, while in Figure 14(b), for $S<0$, the velocity field decreases in the presence of $\gamma \mathrm{Al}_{2} \mathrm{O}_{3}-\mathrm{C}_{2} \mathrm{H}_{6} \mathrm{O}_{2}$ more rapidly than that of $\gamma \mathrm{Al}_{2} \mathrm{O}_{3}-\mathrm{H}_{2} \mathrm{O}$ for the increasing value of $\phi=0,0.04,0.08,0.12$. However, in Figure 15, upon incremental values of solid size segment $\phi$, the velocity $f(\eta)$ decreases for $S>0$ and increases for $S<0$, while in Figure 16, the component of transverse velocity behaves opposite to that of axial velocity for both suction and injection cases.

The impact of emerging parameters on the temperature profile along with the thermal radiation is reflected in Figures 17 and 18.

Figure 17 depicts the impact of radiation parameter $R d$ on temperature profile $\theta(\eta)$. Here, it is observed that, due to remarkable effects of thermal radiation, the temperature distribution increases with incremental values of $R d$ for both $S>0$ and $S<0$.

Figure 18 represents the effects of Prandtl number Pr on the temperature field $\theta(\eta)$ for $\gamma \mathrm{Al}_{2} \mathrm{O}_{3}-\mathrm{H}_{2} \mathrm{O}$ and $\gamma \mathrm{Al}_{2} \mathrm{O}_{3}-\mathrm{C}_{2} \mathrm{H}_{6} \mathrm{O}_{2}$. Here, it depicts the temperature field $\theta(\eta)$ for increasing values of Prandtl number $\operatorname{Pr}=0.72,3.0,6.2$. One can see that temperature field $\theta(\eta)$ increases for increasing values of Prandtl number $\operatorname{Pr}=0.72,3.0,6.2$ for $S>0$ as well as for $S<0$.

Our flow model is of wide range for the nanofluids. In the following, the numerical results are discussed in detail with the help of upper plotted graphs and tables as well. Table 2 reflects the validity of our flow model for $\phi=0$ and $M=0.5$. Here, one can easily notice that, with the existing literature, our flow model is in best agreement to the present study which proves the novelty and reality of our flow model. The upshots of skin friction coefficient and local Nusselt number for $\gamma \mathrm{Al}_{2} \mathrm{O}_{3}-\mathrm{H}_{2} \mathrm{O}$ are portrayed in Table 3, while the ethylene glycol-based nanoparticles are portrayed in Table 4 . To provoke the enhancement of thermal conductivity due to the inclusion of thermal radiation parameter $R d$, one can observe that the rate of heat transfer increases quite rapidly in the 


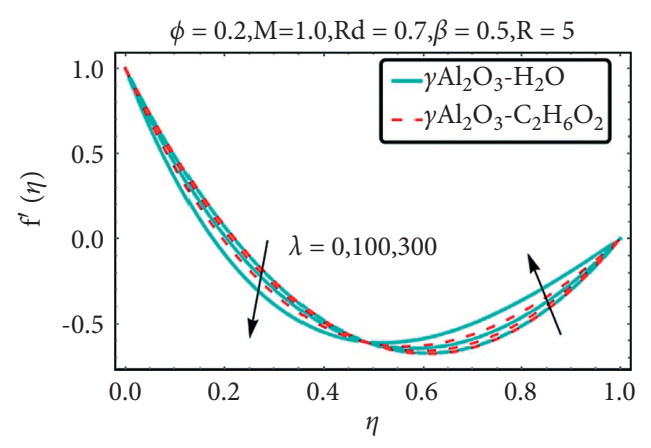

(a)

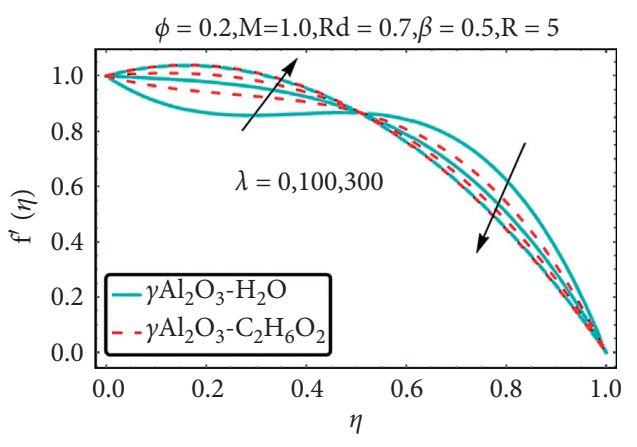

(b)

FIGURE 11: $\lambda$ varying for $f^{\prime}$ with $S$ (suction and injection).

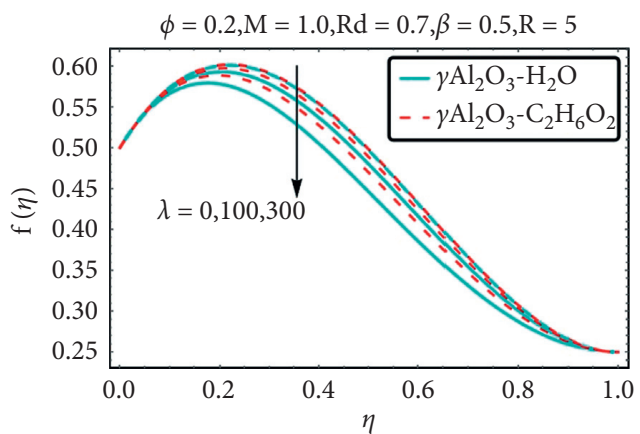

(a)

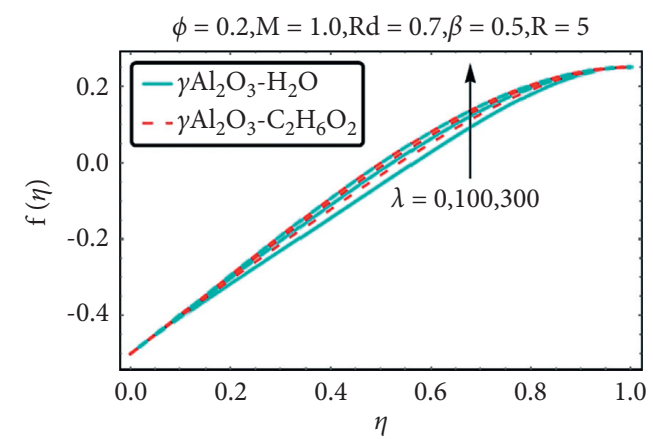

(b)

FIGURE 12: $\lambda$ varying for $f$ with $S$ (suction and injection).

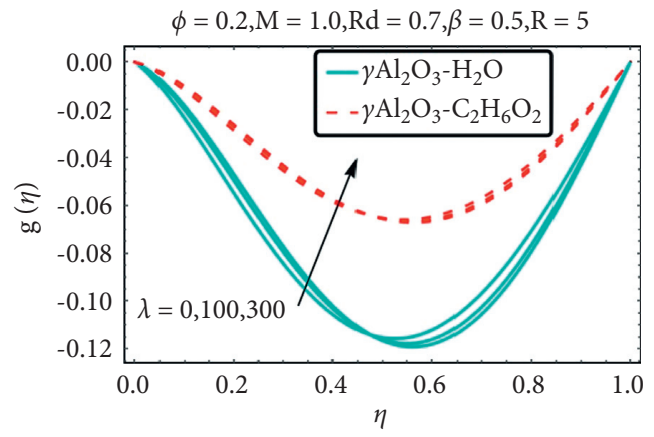

(a)

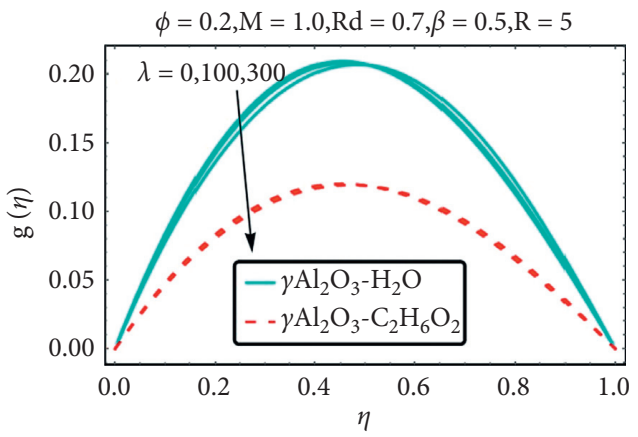

(b)

Figure 13: $\lambda$ varying for $g$ with $S$ (suction and injection).

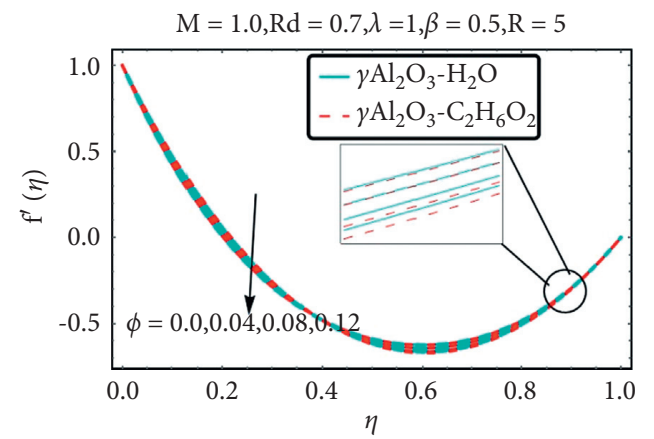

(a)

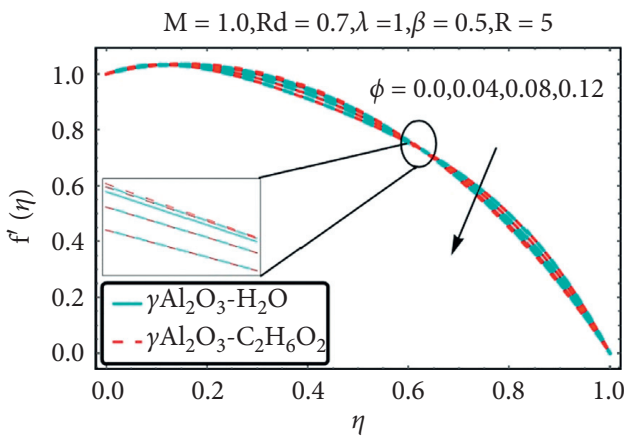

(b)

FIGURE 14: $\phi$ varying for $f^{\prime}$ with $S$ (suction and injection). 


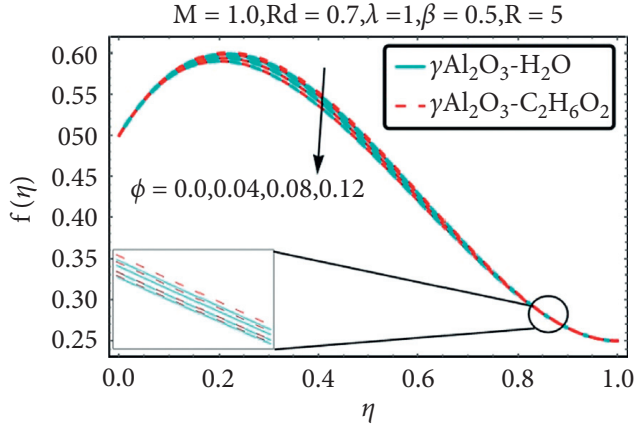

(a)

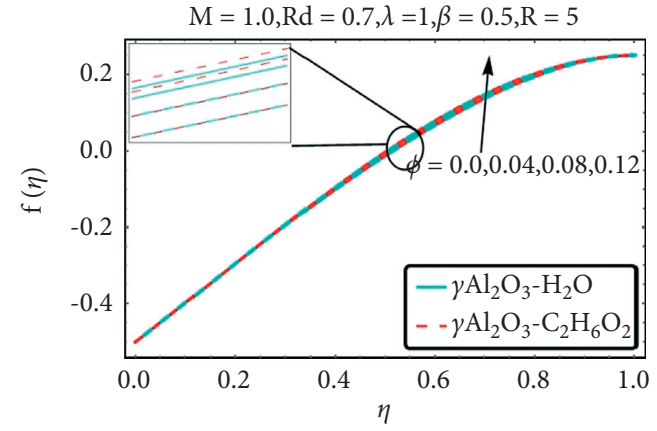

(b)

Figure 15: $\phi$ varying for $f$ with $S$ (suction and injection).

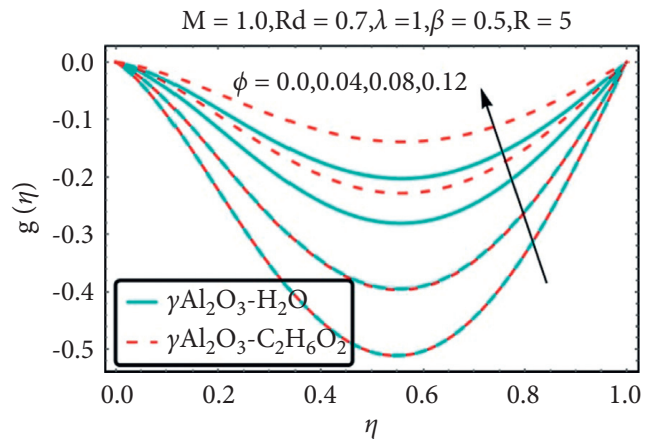

(a)

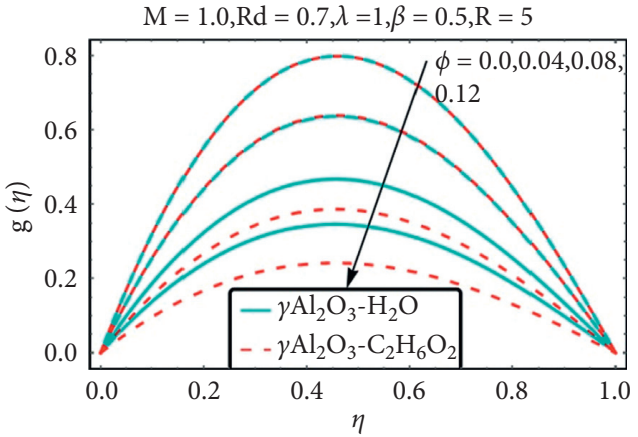

(b)

FIGURE 16: $\phi$ varying for $g$ with $S$ (suction and injection).

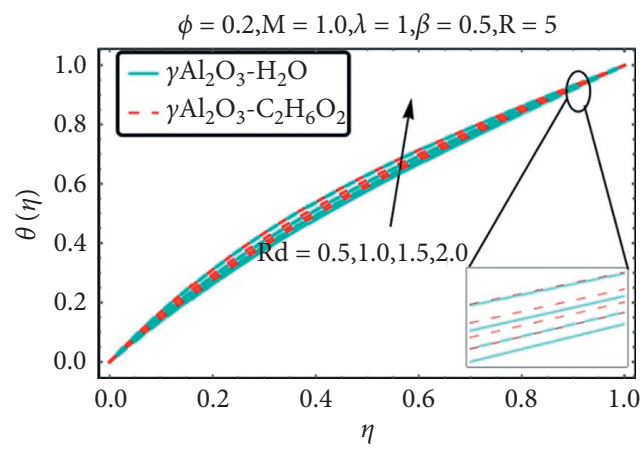

(a)

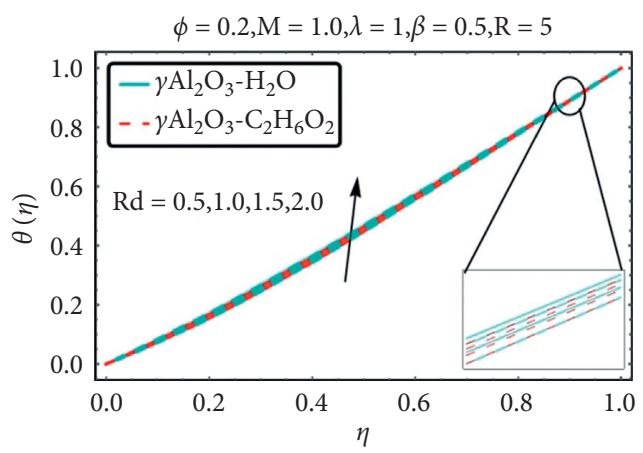

(b)

FIgURE $17 R d$ varying for $\theta$ with $S$ (suction and injection).

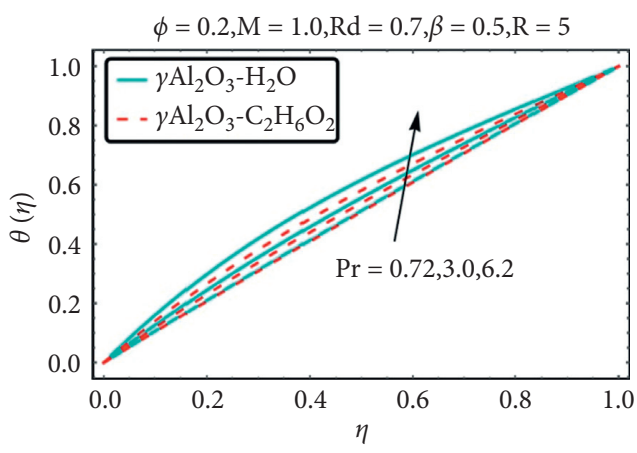

(a)

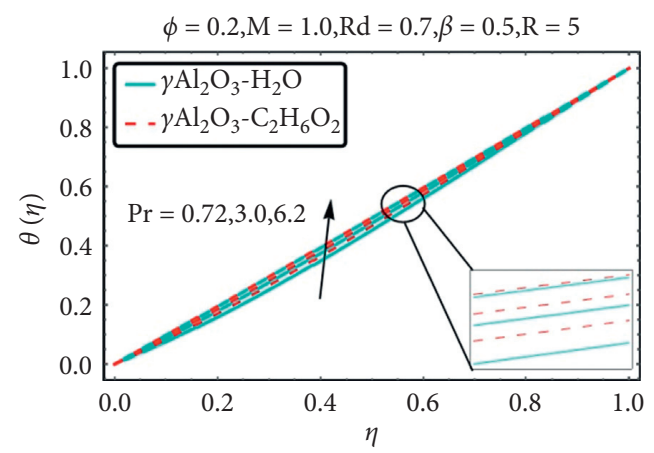

(b)

Figure 18: Pr varying for $\theta$ with $S$ (suction and injection). 
TABLE 2: Comparison with the existing literature for $\phi=0$ and $M=0.5$.

\begin{tabular}{|c|c|c|c|c|c|c|}
\hline \multirow{2}{*}{$\beta$} & \multirow{2}{*}{$R$} & \multirow{2}{*}{$S$} & \multicolumn{2}{|c|}{$f^{\prime \prime}(0)$} & \multicolumn{2}{|c|}{$f^{\prime \prime}(1)$} \\
\hline & & & Present & Khan et al. [4] & Present & Khan et al. [4] \\
\hline-1.0 & 2.0 & 0.5 & -10.53119500 & -10.5311950 & 7.70317226 & 7.7031724 \\
\hline 0.0 & & & -7.58900683 & -7.5890069 & 4.82359091 & 4.8235909 \\
\hline 1.0 & & & -4.51255172 & -4.5125517 & 1.80917188 & 1.8091719 \\
\hline 2.0 & & & -1.28942091 & -1.2894209 & -1.35422925 & -1.3542292 \\
\hline 3.0 & & & 2.08350344 & 2.0835034 & -4.67005029 & -4.6700503 \\
\hline
\end{tabular}

TABle 3: Numerical values of $f^{\prime \prime}(1)$ and $\theta(1)$ for $\gamma \mathrm{Al}_{2} \mathrm{O}_{3}-\mathrm{H}_{2} \mathrm{O}$.

\begin{tabular}{|c|c|c|c|c|c|c|c|c|}
\hline \multirow{2}{*}{$\beta$} & \multirow{2}{*}{$R d$} & \multirow{2}{*}{$R$} & \multirow{2}{*}{$\lambda$} & \multirow{2}{*}{$M$} & \multicolumn{2}{|c|}{$f^{\prime \prime}(1)$} & \multicolumn{2}{|c|}{$\theta^{\prime}(1)$} \\
\hline & & & & & $S>0$ & $S<0$ & $S>0$ & $S<0$ \\
\hline 0.5 & 0.7 & 2 & 1 & 1 & 15.93987 & -11.89738 & -1.23755 & -1.91508 \\
\hline 1 & & & & & 8.99335 & -19.04397 & -1.22456 & -1.89405 \\
\hline 1.5 & & & & & 2.00256 & -26.23351 & -1.21168 & -1.87321 \\
\hline 2 & & & & & -5.03229 & -33.46580 & -1.19891 & -1.85256 \\
\hline \multirow[t]{6}{*}{1} & 0.5 & & & & 34.5299 & -19.04411 & -0.421818 & -1.90666 \\
\hline & 1 & & & & 47.1583 & -19.04380 & -0.643296 & -1.87839 \\
\hline & 1.5 & & & & 60.444 & -19.04357 & -0.884845 & -1.85841 \\
\hline & 1 & 0.5 & & & 8.99335 & -19.01137 & -1.27791 & -1.87831 \\
\hline & & 1.0 & & & 8.99326 & -19.01785 & -1.27791 & -1.87833 \\
\hline & & 1.5 & & & 8.99311 & -19.02866 & -1.27793 & -1.87835 \\
\hline
\end{tabular}

TABle 4: Numerical values of $f^{\prime \prime}(1)$ and $\theta(1)$ for $\gamma \mathrm{Al}_{2} \mathrm{O}_{3}-\mathrm{C}_{2} \mathrm{H}_{6} \mathrm{O}_{2}$.

\begin{tabular}{|c|c|c|c|c|c|c|c|c|}
\hline \multirow{2}{*}{$\beta$} & \multirow{2}{*}{$R d$} & \multirow{2}{*}{$R$} & \multirow{2}{*}{$\lambda$} & \multirow{2}{*}{$M$} & \multicolumn{2}{|c|}{$f^{\prime \prime}(1)$} & \multicolumn{2}{|c|}{$\theta^{\prime}(1)$} \\
\hline & & & & & $S>0$ & $S<0$ & $S>0$ & $S<0$ \\
\hline 0.5 & 0.7 & 2 & 1 & 1 & 15.94174 & -11.8980 & -1.03713 & -1.98610 \\
\hline 1 & & & & & 8.99516 & -19.0446 & -1.02218 & -1.95441 \\
\hline 1.5 & & & & & 2.00432 & -26.2342 & -1.00737 & -1.92310 \\
\hline 2 & & & & & -5.03057 & -33.4665 & -0.99272 & -1.89218 \\
\hline \multirow[t]{6}{*}{1} & 0.5 & & & & 8.99571 & -19.04482 & -0.96640 & -1.97145 \\
\hline & 1 & & & & 8.99450 & -19.04440 & -1.09289 & -1.93310 \\
\hline & 1.5 & & & & 8.99368 & -19.04410 & -1.18506 & -1.90570 \\
\hline & 1 & 0.5 & & & 8.99495 & -19.01197 & -1.09284 & -1.93299 \\
\hline & & 1.0 & & & 8.99486 & -19.01846 & -1.09285 & -1.93301 \\
\hline & & 1.5 & & & 8.99471 & -19.02927 & -1.09287 & -1.93305 \\
\hline
\end{tabular}

case of $\gamma \mathrm{Al}_{2} \mathrm{O}_{3}-\mathrm{C}_{2} \mathrm{H}_{6} \mathrm{O}_{2}$ nanoparticles as compared to $\gamma \mathrm{Al}_{2} \mathrm{O}_{3}-\mathrm{H}_{2} \mathrm{O}$.

\section{Conclusion}

An unsteady nonlinear flow prototype under the influence of thermal radiation comprising the $\gamma$-aluminum particle is presented for $\mathrm{H}_{2} \mathrm{O}$ and $\mathrm{C}_{2} \mathrm{H}_{6} \mathrm{O}_{2}$. The given structure is consolidated iteratively, and the subsequent outcomes are deduced:

(1) For $\gamma-\mathrm{AL}_{2} \mathrm{O}_{3}-\mathrm{H}_{2} \mathrm{O}$, the temperature distribution is higher than $\gamma-\mathrm{AL}_{2} \mathrm{O}_{3}-\mathrm{C}_{2} \mathrm{H}_{6} \mathrm{O}_{2}$

(2) In the presence of the effective Prandtl number, the skin friction coefficient enhanced in buoyancy opposing flow for both nanofluids

(3) For $\gamma-\mathrm{AL}_{2} \mathrm{O}_{3}-\mathrm{C}_{2} \mathrm{H}_{6} \mathrm{O}_{2}$, the skin friction coefficient is higher than $\gamma-\mathrm{AL}_{2} \mathrm{O}_{3}-\mathrm{H}_{2} \mathrm{O}$ in buoyancy opposing flow
(4) The rate of heat transfer is decreased in the absence of the effective Prandtl model, while the opposite trend is observed in the presence of the effective Prandtl model

(5) It is inspected that the transverse component of velocity decreases for increasing values of $\beta$ for $S>0$ and increases for $S<0$

(6) Due to incremental values of $M$, the velocity $f(\eta)$ decreased for $S>0$, and the transverse component of velocity increased

(7) The radiation parameter $R d$ favors the temperature distribution along with the incremental values of the Prandtl number

(8) Mixed convection parameter $\lambda$ opposes the axial velocity

(9) For increasing values of $R d$, the rate of heat transfer increases quite rapidly for the $\gamma \mathrm{Al}_{2} \mathrm{O}_{3}-\mathrm{C}_{2} \mathrm{H}_{6} \mathrm{O}_{2}$ nanoparticles 
(10) Under certain limitations, the skin friction coefficient and rate of heat transfer at both walls show an excellent agreement with the prevailing one

\section{Data Availability}

No data were required to perform this research.

\section{Conflicts of Interest}

The authors declare that they have no conflicts of interest.

\section{Acknowledgments}

Project ZR2020ME100 supported by the Natural Science Foundation of Shandong Province and Project XY21BS42 supported by Heze University Natural Science Foundation are gratefully acknowledged.

\section{References}

[1] M. A. R. Sharif, "Laminar mixed convection in shallow inclined driven cavities with hot moving lid on top and cooled from bottom," Applied Thermal Engineering, vol. 27, no. 5-6, pp. 1036-1042, 2007.

[2] M. Mahmoodi, "Mixed convection inside nanofluid filled rectangular enclosures with moving bottom wall," Thermal Science, vol. 15, no. 3, pp. 889-903, 2011.

[3] A. Arefmanesh and M. Mahmoodi, "Effects of uncertainties of viscosity models for $\mathrm{Al}_{2} \mathrm{O}_{3}$-water nanofluid on mixed convection numerical simulations," International Journal of Thermal Sciences, vol. 50, no. 9, pp. 1706-1719, 2011.

[4] S. I. U. Khan, E. Alzahrani, U. Khan, N. Zeb, and A. Zeb, "On mixed convection squeezing flow of nanofluids," Energies, vol. 13, no. 12, p. 3138, 2020.

[5] S. T. Mohyud-Din, S. I. U. Khan, M. Darus, and S. M. Hassan, "Unsteady mixed convection squeezing flow of nanofluid between parallel disks," Advances in Mechanical Engineering, vol. 8, no. 5, pp. 1-13, 2016.

[6] S. T. Mohyud-Din, S. I. U. Khan, and B. Mohsin, "Velocity and temperature slip effects on squeezing flow of nanofluid between parallel disks in the presence of mixed convection," Neural Computing \& Applications, vol. 28, no. 1, pp. 169-182, 2017.

[7] T. C. Chen and R. Skalak, "Stokes flow in a cylindrical tube containing a line of spheroidal particles," Applied Scientific Research, vol. 22, pp. 403-441, 1969.

[8] S. U. S. Choi, "Enhancing thermal conductivity of fluids with nanoparticle," Developments and Applications of Non-Newtonian Flows, vol. 231, pp. 99-105, 1995.

[9] S. J. Kim, I. C. Bang, J. Buongiorno, and L. W. Hu, "Study of pool boiling and critical heat flux enhancement in nanofluids," Bulletin of the Polish Academy of Sciences, Technical Sciences, vol. 55, no. 2, pp. 211-216, 2007.

[10] S. J. Kim, I. C. Bang, J. Buongiorno, and L. W. Hu, "Surface wettability change during pool boiling of nanofluids and its effect on critical heat flux," International Journal of Heat and Mass Transfer, vol. 50, no. 19-20, pp. 4105-4116, 2017.

[11] P. Kandaswamy, S. Sivasankaran, and N. Nithyadevi, "Buoyancy-driven convection of water near its density maximum with partially active vertical walls," International Journal of Heat and Mass Transfer, vol. 50, no. 5-6, pp. 942-948, 2007.
[12] S. M. Sebdani, M. Mahmoodi, and S. M. Hashemi, "Effect of nanofluid variable properties on mixed convection in a square cavity," International Journal of Thermal Sciences, vol. 52, pp. 112-126, 2012.

[13] A. A. Abbasian Arani, M. Abbaszadeh, and A. Ardeshiri, "Mixed convection fluid flow and heat transfer and optimal distribution of discrete heat sources location in a cavity filled with nanofluid," Challenges in Nano and Micro Scales Science and Technology, vol. 5, no. 1, pp. 30-43, 2019.

[14] T. G. Kashifullah, M. Bilal, W. Alghamdi, M. I. Asjad, and T. Abdeljawad, "Hybrid nanofluid flow within the conical gap between the cone and the surface of a rotating disk," Scientific Reports, vol. 11, no. 1, 2021.

[15] A. Ahmadian, M. Bilal, M. A. Khan, and M. I. Asjad, "Numerical analysis of thermal conductive hybrid nanofluid flow over the surface of a wavy spinning disk," Scientific Reports, vol. 10, no. 1, 2020.

[16] A. Ahmadian, M. Bilal, M. A. Khan, and M. I. Asjad, "The non-Newtonian Maxwell nanofluid flow between two parallel rotating disks under the effects of magnetic field," Scientific Reports, vol. 10, no. 1, 2020.

[17] M. I. Asjad, M. Aleem, A. Ahmadian, S. Salahshour, and M. Ferrara, "New trends of fractional modeling and heat and mass transfer investigation of (SWCNTs and MWCNTs)CMC based nanofluids flow over inclined plate with generalized boundary conditions," Chinese Journal of Physics, vol. 66, pp. 497-516, 2020.

[18] M. Aleem, M. I. Asjad, A. Shaheen, and I. Khan, "MHD Influence on different water based nanofluids $\left(\mathrm{TiO}_{2}, \mathrm{Al}_{2} \mathrm{O}_{3}\right.$, $\mathrm{CuO})$ in porous medium with chemical reaction and Newtonian heating," Chaos, Solitons \& Fractals, vol. 130, Article ID 109437, 2020.

[19] M. I. Asjad, R. Ali, A. Iqbal, T. Muhammad, and Y.-M. Chu, "Application of water based drilling clay-nanoparticles in heat transfer of fractional Maxwell fluid over an infinite flat surface," Scientific Reports, vol. 11, no. 1, 2021. 